\title{
Buckling and vibration analysis of shape memory laminated composite beams under axially heterogeneous in-plane loads in the glass transition temperature region
}

\author{
Nilesh Tiwari ${ }^{1}$ - A. A. Shaikh ${ }^{1}$ \\ Received: 17 October 2020 / Accepted: 25 February 2021 / Published online: 12 March 2021 \\ (c) The Author(s) $2021 \quad$ OPEN
}

\begin{abstract}
Buckling and vibration study of the shape memory polymer composites (SMPC) across the glass transition temperature under heterogeneous loading conditions are presented. Finite element analysis based on $\mathrm{C}^{\circ}$ continuity equation through the higher order shear deformation theory (HSDT) is employed considering non linear Von Karman approach to estimate critical buckling and vibration for the temperature span from 273 to $373 \mathrm{~K}$. Extensive numerical investigations are presented to understand the effect of temperature, boundary conditions, aspect ratio, fiber orientations, laminate stacking and modes of phenomenon on the buckling and vibration behavior of SMPC beam along with the validation and convergence study. Effect of thermal conditions, particularly in the glass transition region of the shape memory polymer, is considerable and presents cohesive relation between dynamic modulus properties with magnitude of critical buckling and vibration. Moreover, it has also been inferred that type of axial loading condition along with the corresponding boundary conditions significantly affect the buckling and vibration load across the glass transition region.
\end{abstract}

Keywords SMP.SMPC · Buckling · Vibration · Glass transition region · HSDT

\section{Introduction}

Shape memory polymers (SMP) possess the feature to deform under the application of stress and regain its original orientation in the vicinity of a stimulus such as electricity, magnetic field, heat, chemical or moisture [1]. Present study focuses on the on the heat sensitive thermoset polymer, which has better thermomechanical properties as it has improved energy storage and robust intermolecular crosslinks [2]. SMPs have the wide span of distinct characteristics of resistance to the harsh environment and shape controllability but has low tensile strength at elevated temperature [3]. The overall mechanical properties can be enhanced with the incorporation of fiber in shape memory polymer composites (SMPC). Hence, new horizons are created for its application such as aerospace [4], electronics[5], biomedical engineering[6] and textile[7].

Laminated composites are in extensive application in civil, aerospace, military and aeronautical avenues because of the enhanced strength, stiffness and lightness which has encouraged numerous investigators to present theories to estimate the mechanical behavior of laminated composites beams (LCB) under various deformations. Among these, Higher order shear deformation theory (HSDT) considers higher order axial distortion variation along thickness of a beam, which results in prediction of behavior for laminated composite beam with improved precision than the classical beam theory (CBT) and First order shear deformation theory [8].

In the last few decades, with advent of some novel applications, laminated SMPCs have also been identified

Nilesh Tiwari, nileshbwtiwari@gmail.com | ${ }^{1}$ Mechanical Engineering Department, Sardar Vallabhbhai National Institute of Technology, Surat 395007, India. 
with great potentials in numerous areas of smart structural applications. Thus, SMPC beams are constantly subjected to numerous elastic instabilities, among which buckling and vibration would be focus of analysis in this paper. In this context, a brief literature review of buckling and vibration study of LCB is summarized. Mathew et al. [9] presented the thermal buckling behavior of LCB through FSDT based finite element method (FEM). Lee [10] evaluated the thermal buckling behavior based on layer-wise theory. Employing, Euler-Bernoulli beam theory, Emam and Nayfeh [11] estimated the post buckling behavior of LCB through Euler-Bernoulli beam theory. Aydogdu $[12,13]$ presented the mechanical and thermal buckling behavior of the LCB for different conditions through Ritz method. Vo and Thai [14] studied buckling and vibration of LCB through HSDT with the consideration of bending and shear components along transverse displacement. Modifying the previous models with consideration of shearing, Eltaher et al. $[15,16]$ presented bending, vibration and buckling behavior of thick nanobeams under the mechanical loading. Nguyen et al. [17] analyzed the thermo-mechanical vibrational and buckling behavior of LCB through novel shape function based on Ritz method. It must be noticed that, buckling can even appear in the ambience of non-uniform variable in plane loading conditions. Some literatures can be found for the buckling and vibration analysis of isotropic structures subjected to nonuniform loadings [18-21]. However, there are few works that focus on the elastic buckling and buckling behavior of laminated composites under influence of non-uniform axially variable in-plane loadings.

Beam structures are exposed to heterogenous in plane loading in real life applications such as aircrafts fins, stiffened plates on marine structures and beam of skyscrapers [22]. Thus, it is significant to study the buckling behavior of beams under non-uniform axially variable loadings. Nemeth [23] analyzed the buckling behavior of LCB under varying in-plane edge load and presented solutions for different fiber orientations and loading conditions. Lopatin and Morozov [24, 25] evaluated the buckling parameters of laminated composite plates subjected to varying in-plane loading. Zhong and Gu [26] analyzed the buckling phenomenon for crossply laminates for variable in plane edge loading through FSDT. Cagdas and Adali [27] optimized the layer thickness for various fiber angle and boundary conditions for the estimation of maximum load resistant to buckling. Based on analytically derived parametric study, Kalyan and Bhaskar [28] performed buckling analysis of orthotropic plate. Kumar et al. [29] presented buckling parameters for skew composite plate under the influence of variable in-plane loading. Mallela and Upadhyay [30] formulated parametric correlations to design composite panel subjected to varying in-plane loading and predicted its buckling behavior. Kim and Lee [31] modelled the buckling behavior of thin LCB subjected to varying loading.

Buckling and vibration study to estimate post-buckling behavior of LCB has rarely been attempted for nonlinear axially heterogenous in-plane loading. Except for some of the works in recent times, most of analysis assumes uniform compressive load throughout the beam or plate. Karamanli and Aydogdu [8] studied the buckling phenomenon in LCB and sandwich under various axially varying in-plane loading through HSDT with Ritz solution. Eltaher et al. [32] presented a model to predict static stability of LCB under varying axial loads. As per the available literature, the study the buckling and vibration phenomenon with their mode-shapes for SMPC beams under the axially heterogeneous in-plane loads has rarely been studied. Based on the inspiration, in the present study, buckling and vibration analysis of SMPC laminated beams subjected to axially varying in-plane load has been investigated. The paper presents buckling and vibrations analysis of SMPC beam for different boundary conditions, aspect ratio, fiber orientation, laminate stacking and modes of phenomenon.

The article is organized as following: Sect. 2 discusses theory of shape memory effect in SMPC and mathematical formulation incorporated in finite element analysis. Section 3 presents the results obtained through the evaluation of finite element analysis (FEA), which include convergence and validation study followed with the analysis of influence of different factors on the buckling and vibration on SMPC beam. Section 4 describes the conclusion inferred through the numerical study.

\section{Theory and formulation}

The theory to estimate the dynamic mechanical parameters of smart polymer matrix with the incorporation of carbon fiber in the composite is discussed followed with the formulation of buckling and vibration analysis through FEA.

\subsection{Modelling of shape memory effect}

The material characteristics of the temperature regulated polymer is referred from an experimental work in Ref. [33]. Analytical correlation in terms of Eq. (1) is formulated though curve fitting of experimental data, to estimate storage modulus $E(T)$ of SMP for the varying temperature condition across $T_{g}$ [34]. 
$E(T)=\left(E_{1}-E_{2}\right) \cdot \exp \left(-\left(\frac{T}{T_{\beta}}\right)^{m_{1}}\right)+\left(E_{2}-E_{3}\right) \cdot \exp \left(-\left(\frac{T}{T_{g}}\right)^{m_{2}}\right)+E_{3} \cdot \exp \left(-\left(\frac{T}{T_{f}}\right)^{m_{3}}\right)$

where $T$ is the span of temperature considered for analysis. $E_{1}, E_{2}$ and $E_{3}$ are SMP's moduli at the commencement of glass transition temperature $\left(T_{\beta}\right)$, glass transition temperature $\left(T_{g}\right)$ and flow region temperature $\left(T_{f}\right)$ respectively. $m_{1}, m_{2}$ and $m_{3}$ are Weibull exponents for optimized curvefitting. These values to be substituted in Eq. (1) has been obtained from the work by Gu et al. [41], summarized in Table 1. Experimentally determined values of parameter were extracted through Dynamic mechanical Analysis (DMA). Data of experiments and the subsequent confirmation by Eq. (1) is depicted in Fig. 1a, which highlights considerable convergence. Storage modulus has been assumed as Elastic modulus in the following stages of analysis, due to negligible magnitude of loss modulus than the storage modulus [35]. Temperature governed Poisson's ratio $(\mu)$ is evaluated by phase transition model for the matrix [36].

$\mu=\mu_{g} v_{g}+\mu_{r}\left(1-v_{g}\right)$

$v_{g}=1-\frac{1}{1+\exp \left[-\left(T-T_{m}\right) / Z\right]}$

where $\mu_{g}$ and $\mu_{r}$ are Poisson's ratio of the frozen and active phase respectively. $v_{g}$ is the volume fraction of the frozen phase. $T_{m}$ is reference temperature. $Z$ is parameter

Table 1 Values of parameters in model for SMP [35]

\begin{tabular}{|c|c|c|c|c|c|c|c|c|c|c|c|}
\hline Parameter & $T_{g}$ & $T_{m}$ & $T_{\beta}$ & $T_{f}$ & $E_{1}$ & $E_{2}$ & $E_{3}$ & $m_{1}, m_{2}, m_{3}$ & $\mu_{g}$ & $\mu_{r}$ & \\
\hline alues & $305 \mathrm{~K}$ & $300.5 \mathrm{~K}$ & $295.2 \mathrm{~K}$ & $415.5 \mathrm{~K}$ & $2.552 \mathrm{GPa}$ & $1.876 \mathrm{GPa}$ & $5 \mathrm{MPa}$ & $19.3,58.4,177.6$ & 0.35 & 0.499 & \\
\hline
\end{tabular}

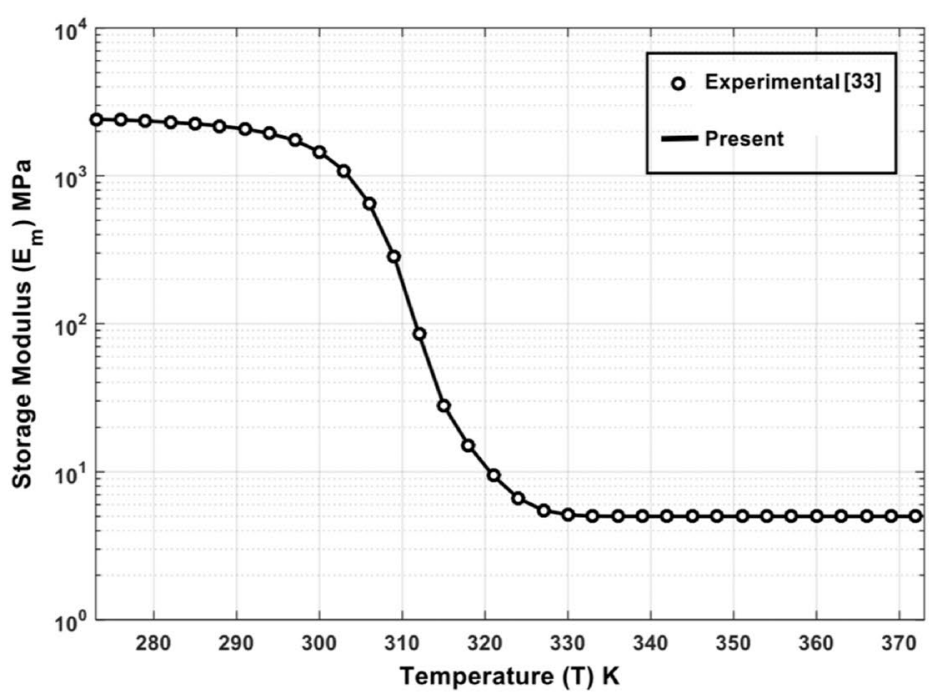

(a)

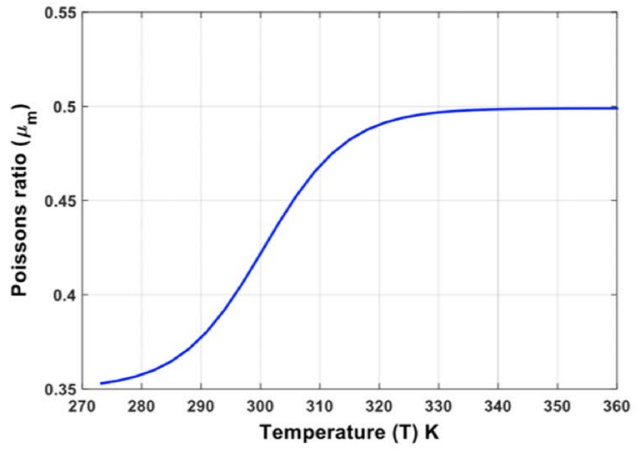

(b)

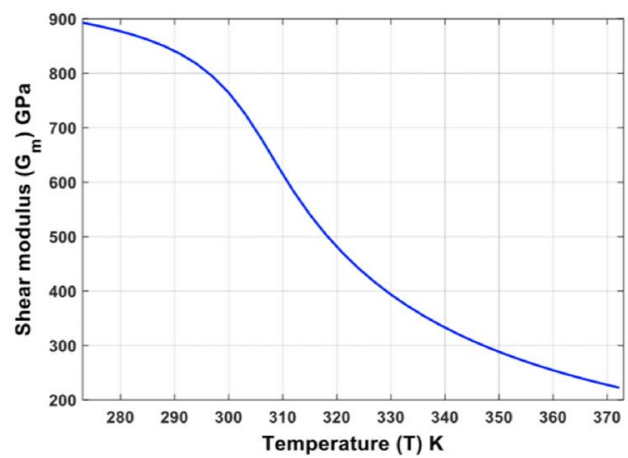

(c)

Fig. 1 Material properties of SMP with respect to temperature (T). a Simulation of Storage modulus with experiment. b Poisson's ratio. c Shear modulus 


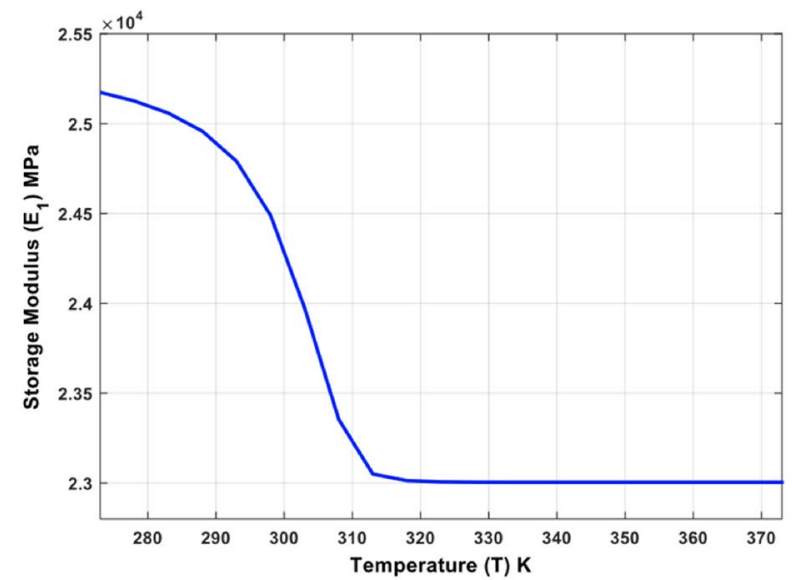

(a)

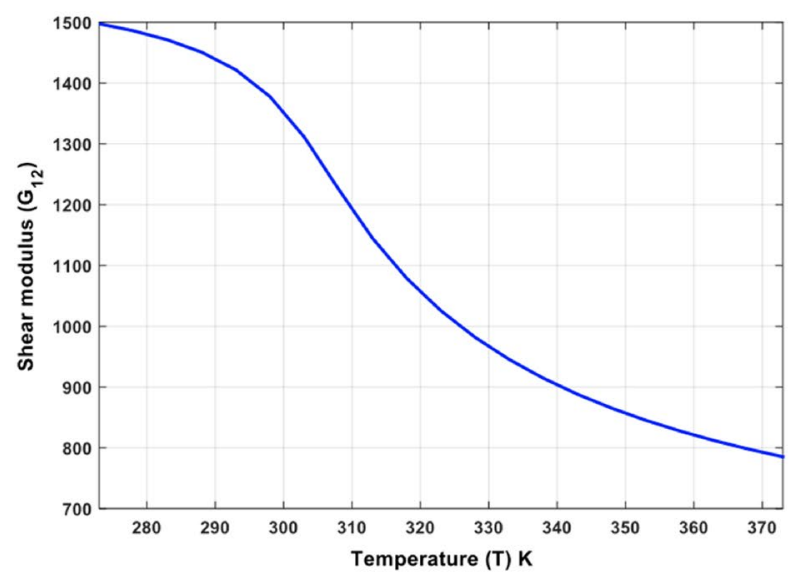

(c)

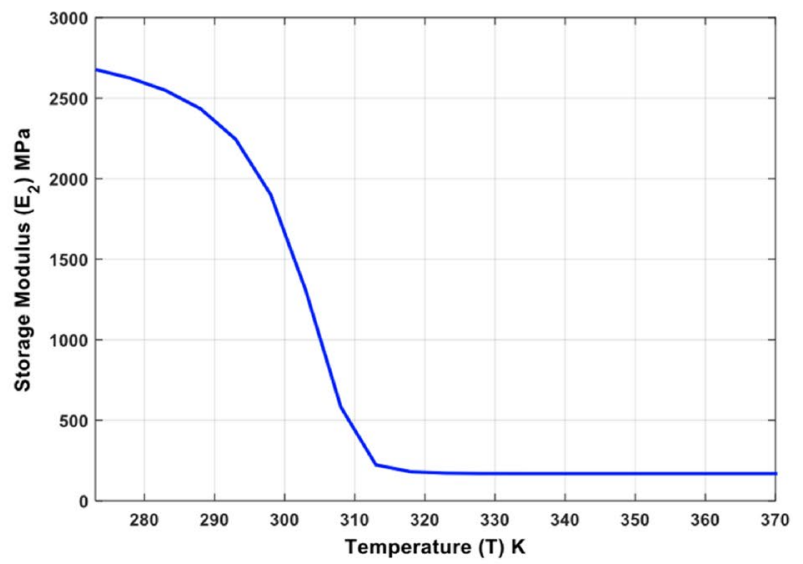

(b)

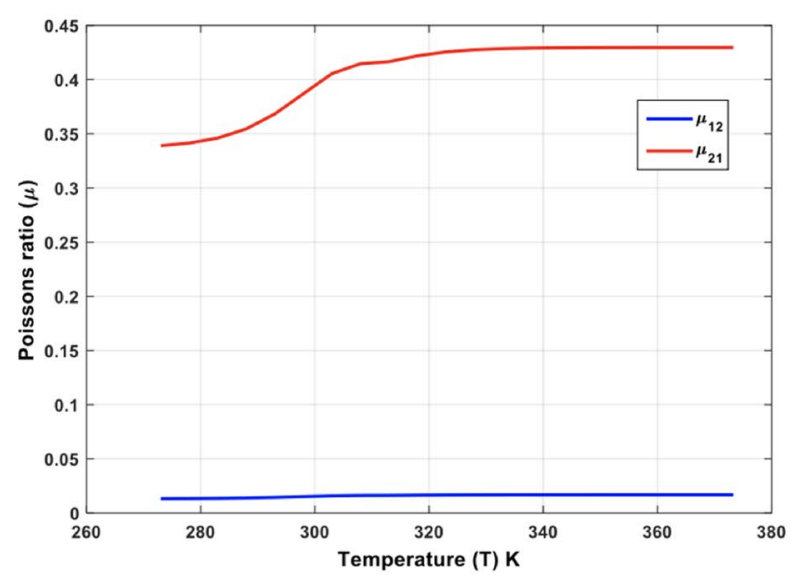

(d)

Fig. 2 Influence of variation of temperature on modulus of SMPC: a longitudinal, $\mathbf{b}$ transverse, $\mathbf{c}$ shear modulus and $\mathbf{d}$ Poissons ratio of SMPC

characterizing the width of the phase transition zone. These material parameters are utilized in the following stage to evaluate the moduli of the SMPC beam under the influence of varying temperature in the vicinity of transition region of polymer matrix. Temperature dependent Poisson's ratio and shear modulus are described in Fig. 2.

The properties of SMPC is estimated by the theory of volume averaging [37] through Eqs. (4-8), which are successively utilized to analyze the behavior of the laminate under different loadings.

$E_{c 1}=E_{f 1} v_{f}+E_{m} v_{m}$

$E_{c 2}=(1-C) E_{c 2}^{1}+C E_{c 2}^{2}$ $\mu_{c 21}=(1-C) \mu_{c 21}^{1}+C \mu_{c 21}^{2}$

$\mu_{c 12}=\mu_{c 21} \frac{E_{c 2}}{E_{c 1}}$

$G_{c 12}=(1-C) G_{c 12}^{1}+C G_{c 12}^{2}$

where $E_{c 1}$ and $E_{c 2}$ are longitudinal and transverse modulus of composite respectively and $E_{f 1}$ and $E_{f 2}$ are the corresponding values for the fiber. $G_{f 12}$ and $G_{c 12}$ are the shear modulus along plane 1-2. For fiber and composite respectively. $\mu_{c 12}$ and $\mu_{c 21}$ are Poisson's ratio of composites in 1-2 and 2-1 plane. The superscript 1 and 2 indicate values of constants in series and parallel respectively and corresponding properties are calculated by Eqs. (9-12), and respectively substituted to evaluate the properties of 
Table 2 Material parameters of carbon fiber [37]

\begin{tabular}{llllll}
\hline Parameters & $E_{f 1}$ & $E_{f 2}$ & $G_{f 12}$ & $\mu_{f}$ & $C$ \\
\hline Magnitude & $2.30 \times 10^{5} \mathrm{MPa}$ & $8.20 \times 10^{3} \mathrm{MPa}$ & $2.73 \times 10^{4} \mathrm{MPa}$ & 0.25 & 0.20 \\
\hline
\end{tabular}

SMPC. The properties of fiber reinforcement are summarized in Table 2. These temperature regulated properties of SMPC are presented in Fig. 2.

$E_{c 2}^{1}=\frac{E_{f 2} E_{m}}{E_{f 2} v_{m}+E_{m} v_{f}}$

$E_{c 2}^{2}=E_{f 2} v_{f}+E_{m} v_{m}$

$\mu_{c 21}^{1}=\mu_{f} v_{f}+\mu_{m} v_{m}$

$\mu_{c 21}^{2}=\frac{\mu_{f} E_{f 2} v_{f}+\mu_{m} E_{m} v_{m}}{E_{f 2} v_{f}+E_{m} v_{m}}$

$G_{c 12}^{1}=\frac{G_{f 12} G_{m}}{G_{f 12} v_{m}+G_{m} v_{f}}$

$G_{c 12}^{2}=G_{f 12} v_{f}+G_{m} v_{m}$

\subsection{Mathematical formulation}

The mathematical formaution of FEM is based on the governing equation presented in Ref. [38]. One dimensional LCB is employed in the present study subjected to varying inplane heterogeneous load. LCB has the length, breadth and thickness as ' $a$,' ' $b$ ' and ' $t$ ' respectively (Fig. 3). Displacement field equations in ' $x$ ' and ' $z$ ' coordinate through the HSDT considering $\mathrm{C}^{\circ}$ continuity equation is given as [38],

$\bar{u}(x, z)=\boldsymbol{u} .+\left(C_{1} z-C_{2} z^{3}\right) \Psi_{x}+\left(-C_{2} Z^{3}\right) \emptyset_{x} ; \bar{w}(x, z)=\boldsymbol{w}$.

where $\boldsymbol{u}, \boldsymbol{w}$, and $\emptyset=\partial w / \partial x$ are displacement along midplane axis, displacement along transverse direction, rotation of normal to the mid-plane along ' $y$ '- axis and slope along ' $x$ '- axis, respectively, with $C_{1}=1, C_{2}=\frac{4}{3} h^{2}$.

Displacement vector for the modified $\mathrm{C}^{3}$ continuous model with four degrees of freedom can be expressed as [38]

$\{q\}=\left[\begin{array}{llll}u & w & \emptyset_{x} & \Psi_{x}\end{array}\right]^{T}$

\subsubsection{Stress, strain and displacement relation}

Here, total strain is the combination of linear $\left\{\bar{\varepsilon}^{L}\right\}$ and nonlinear strain vector $\left\{\bar{\varepsilon}^{N L}\right\}$ with von Karman nonlinearity, stated as [39]

$\{\overline{\boldsymbol{\varepsilon}}\}=[B]\{\boldsymbol{q}\}+\frac{1}{2}\left[A_{n l}\right]\left\{\emptyset_{n l}\right\}$

$[B]$ is the geometrical matrix given in A1. Similarly, plane stress and total strain relationship can be expressed as,
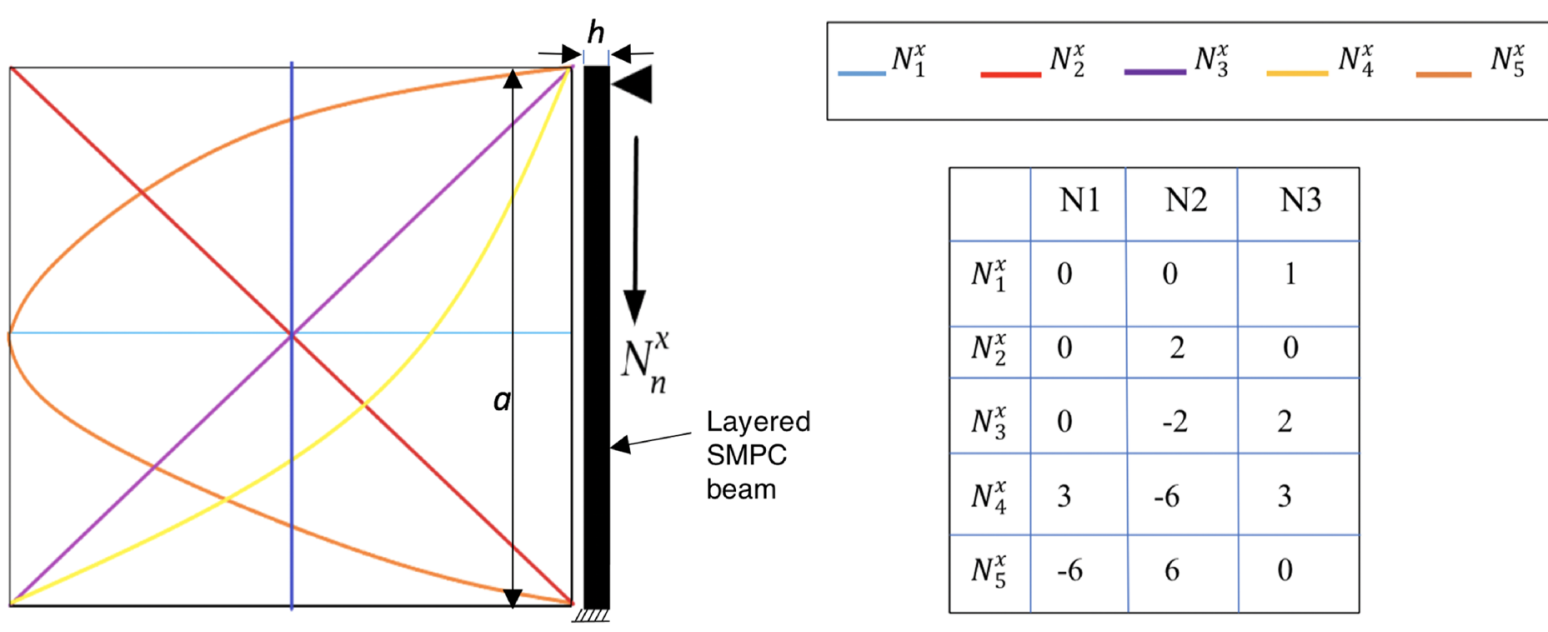

\begin{tabular}{|l|l|l|l|}
\hline & $\mathrm{N} 1$ & $\mathrm{~N} 2$ & $\mathrm{~N} 3$ \\
\hline$N_{1}^{x}$ & 0 & 0 & 1 \\
\hline$N_{2}^{x}$ & 0 & 2 & 0 \\
\hline$N_{3}^{x}$ & 0 & -2 & 2 \\
\hline$N_{4}^{x}$ & 3 & -6 & 3 \\
\hline$N_{5}^{x}$ & -6 & 6 & 0 \\
\hline
\end{tabular}

Fig. 3 Geometrical configuration of composite beam [8] 
$\left\{\begin{array}{c}\overline{\boldsymbol{\sigma}_{\mathbf{x}}} \\ \overline{\boldsymbol{\tau}}_{\mathbf{x z}}\end{array}\right\}=\left[\begin{array}{cc}\overline{Q_{11}} & 0 \\ 0 & \overline{Q_{55}}\end{array}\right]\{\{\bar{\varepsilon}\}\}$

In above expression, transformed reduce matrix denoted is denoted by $\left\{\overline{Q_{i j}}\right\}$ [39].

\subsubsection{FEA of the composite beam}

$C^{0}$ continuity equation employing 1-D Hermitian beam element with four degrees of freedom per node is considered [38]. Rewritten as the following type of beam element geometry and the displacement vector.

$\{\boldsymbol{q}\}=\sum_{i=1}^{N N} N_{i}\{\boldsymbol{q}\}_{i} ; x=\sum_{i=1}^{N N} N_{i} x_{i} ;$

In order to calculate transverse displacement and slope, linear interpolation for axial displacement and rotation of normal and Hermite cubic interpolation functions are considered. Using FEM, Eq. (19) can be remodeled as,

$\boldsymbol{\Pi}_{1}=\sum_{e=1}^{N E} \boldsymbol{\Pi}_{a}^{(e)}=\sum_{e=1}^{N E}\left(\boldsymbol{U}_{L}^{(e)}+\boldsymbol{U}_{N L}^{(e)}\right)$

where $N E$ and $(e)$ denote the number of elements and elemental, respectively.

Equation (20) can be further evaluated as,

$\boldsymbol{\Pi}_{1}=\frac{1}{2} \sum_{e=1}^{N E}\left[\{\boldsymbol{q}\}^{T(e)}\left[K_{l}+K_{n l}\right]^{e}\{\boldsymbol{q}\}^{(e)}\right]=\{\boldsymbol{q}\}^{T}\left[K_{l}+K_{n l}\right]\{\boldsymbol{q}\}$

where $\left[K_{l}\right]$ is global linear matrix, $\left[K_{n / 1}\right],\left[K_{n / 2}\right]$ and $\left[K_{n / 3}\right]$ are non-linear stiffness matrices and $\{\boldsymbol{q}\}$ is global displacement vector.

Work done due to in-plane variable non-uniform loading can be represented as follows [38], first variation of $\left(\Pi_{1}-\Pi_{2}+\Pi_{3}\right)$ with respect to generalized displacement vector is given by,

$\left\{\left[K_{L}+K_{N L}\right]-\lambda\left[K_{G}\right]\right\}\{\boldsymbol{q}\}=0$

$[K]\{\boldsymbol{q}\}=\lambda\left[K_{G}\right]\{\boldsymbol{q}\}$

$[K]\{\boldsymbol{q}\}=\omega^{2}[M]\{\boldsymbol{q}\}$

$[K]=\left\{\left[K_{i}\right]+\left[K_{n l}\right]-\left[K_{G}\right]\right\}$

where $\left[K_{G}\right]$ is the geometric stiffness matrix given in $A 3, \lambda$ is the buckling load parameters, $\omega$ is the natural frequency of the beam, $[M]$ is the global consistent mass matrix and $\{q\}$ is the transverse deflection. The solutions of the above standard equations are obtained by Newton Raphson method which is the most popular solution method due to its quick convergence.

\section{Result and discussions}

FEA analysis of SMPC beam has been performed through a MATLAB program, through the mathematical modelling described in Sect. 2. The results evaluated by means of this program are presented in this section which is distributed in three sub-sections. The first sub-section will compile the validation and comparison of numerical analysis with the previous works. In the second subsection, buckling analysis of SMPC laminated beam will be performed for the axially varying in-plane load. Effect of $\mathrm{BCs}$, orientation of fiber, aspect ratio and laminate ply-staking on buckling behavior of SMPC beam would be presented in this sub-section in the glass transition region of SMPC. Buckling shape mode analysis are also incorporated to visualize effects of dif-

$\boldsymbol{\Pi}_{2}=\frac{1}{2} \iint N_{n}^{x}\left\{\frac{\partial u}{\partial x}\right\}^{2} d A \quad$ where, $\quad N_{n}^{x}=N\left[P_{1}\left(x+\frac{a}{z}\right)^{2}+P_{2}\left(x+\frac{a}{z}\right)+P_{3}\right]$

$\mathrm{P}_{1}, \mathrm{P}_{2}$ and $\mathrm{P}_{3}$ are the in-plane load varying coefficients as shown in the Fig. 3.

Kinetic energy of vibrating sandwich composite beam can be expressed as [40],

$\Pi_{3}=\frac{1}{2} \iiint \rho\{\hat{u}\}^{T}\{\hat{u}\} d v$

$\rho$ is the density of the beam, $\{\dot{\hat{u}}\}$ is the velocity vector. Mechanically induced buckling and vibrational analysis of the in-plane variable heterogenous loading over laminated composite beam evaluated by the minimization of ferent BCs and dynamic thermal property of SMPC. Third subsection presents vibration analysis of SMPC beam.

\subsection{Convergence and validation}

The number of elements (neL), adopted for FEA, is based on the convergence study presented in Fig. 4a. Convergence study are performed for three boundary conditions (BCs) of clamped (C-C), clamped-free (C-F), hinged $(\mathrm{H}-\mathrm{H})$ and clamped-hinged $(\mathrm{C}-\mathrm{H})$ with the consideration of two aspect ratios $(\mathrm{a} / \mathrm{h})-5$ and 10 . Nondimensional 


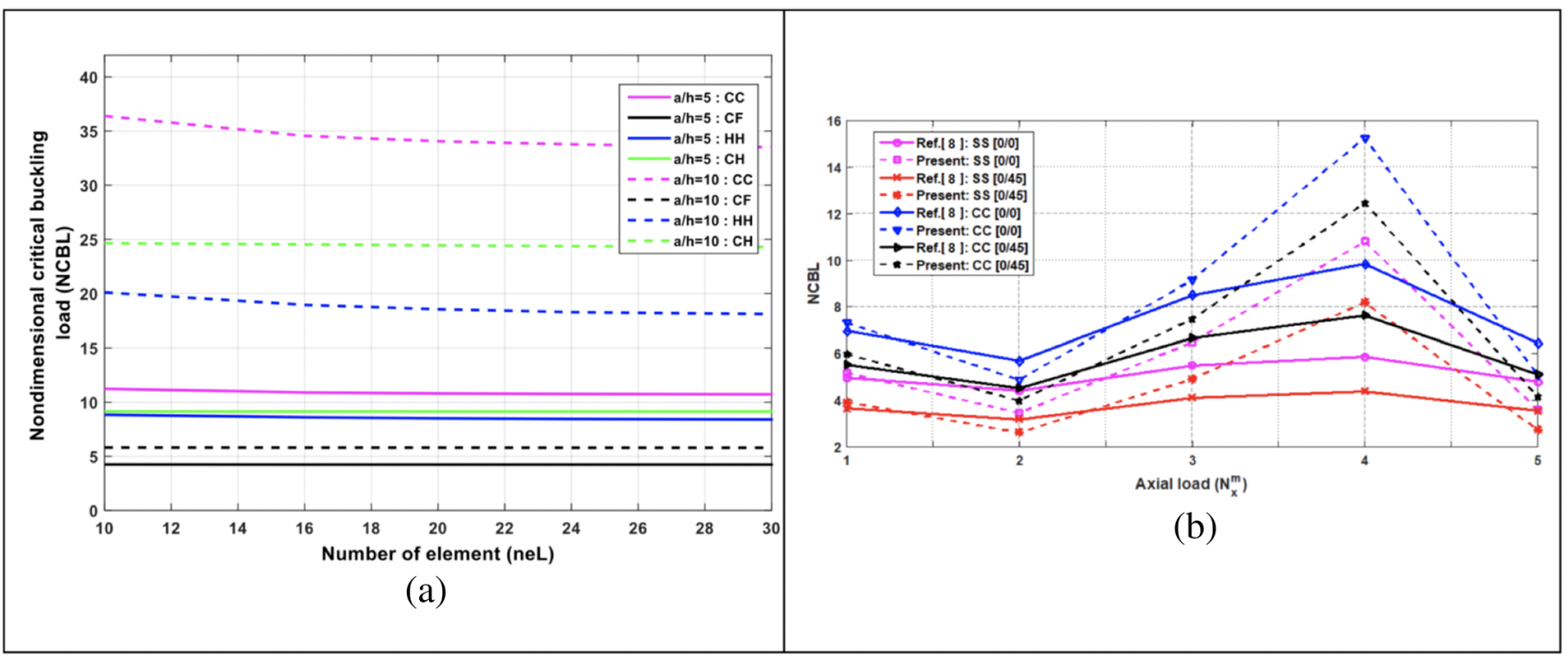

Fig. 4 Convergence and validation of NCBL. a NCBL with respect to neL for different aspect ratios and BCs. b NCBL for different axial loadings

Critical Buckling Load (NCBL) inversely proportional to neL from 10 to 18 , where the slope is considerably higher. In the range of $18-26$, the trajectory stabilizes, with minimal deviation after 30 . Thus, neL $=30$ has been selected for FEA, to obtain results with the minimum number of elements for reducing computation without diluting the accuracy.

The results of buckling analysis for different axial loading conditions are indicated in Fig. 4b, with the corresponding comparison with results indicated in [8]. Evaluation of NCBL has been done for simply supported (S-S) and clamped (C-C) BCs, for 5 different axial loading conditions with unidirectional $\left[0^{\circ} / 0^{\circ}\right]$ and asymmetric $\left[0^{\circ} / 45^{\circ}\right]$ fiber orientation. The analysis presents considerable convergence with the prior works where the highest NCBL for $N_{4}^{m}$ type axial loading. The range of deviation between the results by current analysis and [8] ranges from $4 \%$ for $N_{1}^{m}$ type loading to $31 \%$ for $N_{4}^{m}$ type loading. NCBL can be calculated from Eq. (28) with the consideration of material properties as $E_{1}=25 E_{2}, G_{12}=0.5 E_{2}=G_{13}, G_{23}=0.2 E_{2}$, $\mu_{12}=0.25[8]$.
$N C B L=\frac{\lambda \cdot L^{2}}{E_{1} b h^{3}}$

Results of vibration analysis, with its comparison with the previous works [41], are compiled in Table 3. The parameters assumed in this study are: $E_{1}=21 \times 10^{6}$; $E_{2}=1.4 \times 10^{6} ; G_{12}=0.6 \times 10^{6} ; \mu_{12}=0.3 ;=0.13 \times 10^{-3} ; G_{23}$ $=0.5 \times 10^{6} ; G_{13}=G_{12}$ and $\mu_{12}=0.3 \times E_{2} / E_{1}$. Evaluated values are in congruence with previous results, as indicated in Table 3. Nondimensional Critical frequency $\left(\omega_{c r}\right)$ of beam with aspect ratio of 15 and fiber orientation of $\left[0^{\circ} / 90^{\circ} / 90^{\circ} / 0^{\circ}\right]$ are estimated by Eq. 29 as,

$\omega_{c r}=\frac{\omega \cdot a^{2}}{\rho / 4 E_{1} \cdot h^{2}}$.

\subsection{Buckling analysis}

Parametric study of buckling behavior of smart LCB is discussed in this section. The values of NCBL is stable before the initiation of glass transition, i.e. $T=T_{\beta}$, then

Table 3 Comparison of evaluated critical frequency with [41]

\begin{tabular}{lllllllll}
\hline BCs & Present & Reference [41] & Present & Reference [41] & Present & Reference [41] & Present \\
& $\omega_{1}$ & & $\omega_{2}$ & & $\omega_{3}$ & & $\omega_{4}$ & Reference [41] \\
\hline CC & 4.910 & 4.59 & 11.080 & 10.291 & 18.38 & 16.966 & 26.20 & 24.041 \\
CS & 3.55 & 3.525 & 9.6 & 9.442 & 16.78 & 16.384 & 24.42 & 23.685 \\
CF & 0.925 & 0.9241 & 4.94 & 4.893 & 11.67 & 11.44 & 17.257 & 18.697 \\
SS & 2.50 & 2.50 & 8.545 & 8.545 & 15.95 & 15.85 & 23.72 & 23.71 \\
\hline
\end{tabular}


it abruptly declines to regain stability after $313 \mathrm{~K}$. Buckling behavior of SMPC is in coherence with the results of Fig. 1. Decrease in NCBL of 52.94\%, 50.02\%, 49.93\%, $37.51 \%$ and $48.04 \%$ has been observed for $N_{1}^{m}, N_{2}^{m}, N_{3}^{m}$, $N_{4}^{m}$ and $N_{5}^{m}$ types of load distribution respectively for clamped (C-C) BC. For clamped free (C-F) BC, decline in NCBL by $16.67 \%, 15.08 \%, 16.22 \%, 16.39 \%$ and $64.28 \%$ are noticed in corresponding $N_{1}^{m}, N_{2}^{m}, N_{3}^{m}, N_{4}^{m}$ and $N_{5}^{m}$ types loading. Similar drastic slump in has also been observed in other four BCs, which is coherence with the results of dynamic mechanical analysis in Fig. 1.

Effects of BCs of SMPC laminated composite is depicted in Fig. 5 for clamped (C-C), clamped free (C-F), clamped hinged $(\mathrm{C}-\mathrm{H})$, hinged $(\mathrm{H}-\mathrm{H})$, clamped simply supported (C-S) and simply supported (S-S) boundary conditions. Aspect ratio $(\mathrm{a} / \mathrm{h})$ of 5 with fiber orientation $\left[0^{\circ} / 90^{\circ} / 0^{\circ}\right]$ has been considered for the buckling analysis due to varying in-plane loading condition across glass transition temperature of SMPC. Results depict the effect of different loads across the temperature range from 273 to $373 \mathrm{~K}$ in terms non-dimensional critical buckling load (NCBL), which is highest in case of clamped boundary condition. Among all the load distributions, $N_{3}^{m}$ and $N_{4}^{m}$ types load distribution have higher critical buckling load as compared to uniform distribution $\left(N_{1}^{m}\right)$, while $N_{2}^{m}$ and $N_{5}^{m}$ load distributions have lower critical buckling load than $N_{1}^{m}$. This observation holds true for all the six BCs considered in the analysis. Clamped (CC) BC has maximum critical buckling load, whereas clamped-free (C-F) has the minimum critical buckling load. Ascending order of NCBL in terms of BCs is arranged as C-F, S-S, H-H, C-S, $\mathrm{C}-\mathrm{H}$ and $\mathrm{C}-\mathrm{C}$, which is indicated in Table 4.

Temperature is also be noticed to govern the buckling behavior of SMPC for all the BCs. Critical buckling load is stable before the glass transition region of SMPC, that is, $295 \mathrm{~K}$. However, NCBL suddenly declines after $295 \mathrm{~K}$ and stabilizes after $313 \mathrm{~K}$, which is after the glass transition region. Thus, DMA can be referred to understand the volatile behavior in the glass transition region for buckling analysis of SMPC, as indicated by trajectory in Fig. 5 which fundamentally seems to be govern by results in Fig. 1.

Effect of aspect ratio from 5 to 50 on the critical buckling load under varying load for the six BCs at $T_{g}$ is described in Table 4. In the case of C-C, NCBL increases by $147.90 \%$, $58.56 \%$ and $19.61 \%$ when aspect ratio increases from 5 to 10,10 to 20 and 20 to 50 respectively for all the varying loading conditions, indicating stability of buckling behavior with the increase of aspect ratio. Similar behaviors are noticed in C-S and S-S BCs. 99.73\%, 33.77\% and 10.47\% increase of NCBL is noticed with the respective increase of aspect ratio from 5 to 10,10 to 20 and 20 to 50 in C-S and S-S boundary conditions for all considered loading conditions. However, for the $\mathrm{C}-\mathrm{F}, \mathrm{C}-\mathrm{H}$ and $\mathrm{H}-\mathrm{H}$ BCs, an uneven behavior in the variation of critical buckling load is observed. Difference of $107.67 \%, 51.53 \%$ and $56.36 \%$ for aspect ratio from 5 to 10,10 to 20 and 20 to 50 respectively are calculated in $\mathrm{C}-\mathrm{H}$ boundary condition, while $66.77 \%$, $44.57 \%$ and $90.39 \%$ variations in the similar aspect ratio range of $\mathrm{H}-\mathrm{H}$ boundary condition for all the loading types. Dynamic temperature condition also affects the behavior of SMPC, as evident in Fig. 4 with the constant aspect ratio of 5 , indicating a corresponding regulating influence of critical buckling load for all BCs.

Downward trends are observed as the angle of fiber orientation increases from $0^{\circ}$ to $90^{\circ}$, as presented in Table 5 . NCBL are reported for four layered symmetric SMPC clamped with aspect ratio of 20 . The decrease of $5.97 \%$, $17.47 \%, 29.11 \%, 41.11 \%, 50.83 \%$ and 37.59 is observed for all loading condition across the glass transition region, when fiber orientation is increased from $0^{\circ}$ to $90^{\circ}$ with the interval of $15^{\circ}$. Temperature also play a vital on buckling behavior of SMPC laminate at different fiber orientations. During the shift from pre-glass transition to $T_{g}$, decrease in NCBL by $6.54 \%, 6.17 \%, 5.36 \%, 5.37 \%, 9.72 \%, 27.24 \%$ and $50.52 \%$ is noted for interval of $15^{\circ}$ from $0^{\circ}$ to $90^{\circ}$. Corresponding decrease of NCBL from pre-glass transition to post-glass transition is $15.27 \%, 14.56 \%, 12.911 \%, 12.38 \%$, $19.30 \%, 49.94 \%$ and $91.58 \%$. Thus, temperature also affect the buckling behavior at different fiber orientations for all the considered loading conditions.

Influence of laminate stacking is presented in Table 6 for four BCs under $N_{1}^{m}$ type of loading condition. Among the considered sequences, unidirectional laminate $\left[0^{\circ} / 0^{\circ} / 0^{\circ} / 0^{\circ}\right]$, has the maximum NCBL for all the BCs. It is observed that when the outer layers have ply angle of $0^{\circ}$, NCBL is on a higher magnitude but, as the value proceed towards $90^{\circ}, \mathrm{NCBL}$ decreases.

Effect of glass transition region of SMPC and different types of buckling modes at glass transition temperature is discussed through Table 7 and Fig. 6, in this section. NCBL for four buckling modes at three temperatures of $T=T_{\beta}, T_{g}$ and $T_{f}$ with the consideration of linearity and nonlinearity are presented in Table 7. Prior to the beginning of glass transition, NCBL decreases by $0.14 \%$ and $0.42 \%$ in Mode- $1,0.09 \%$ and $0.29 \%$ in Mode- $2,0.13 \%$ and $0.41 \%$ in Mode- 3 and $0.13 \%$ and $0.41 \%$ in Mode- 4 with the assumption of nonlinearity of $W_{\max } / h=0.1$ and 0.2 respectively as compared to linearity. At glass transition temperature, $T_{g}$ NCBL decreases by $0.18 \%$ and $0.55 \%$ in Mode- $1,0.12 \%$ and $0.38 \%$ in Mode- $2,0.19 \%$ and $0.58 \%$ in Mode- 3 and $0.19 \%$ and $0.59 \%$ in Mode- 4 with the assumption of nonlinearity of $W_{\max } / h=0.1$ and 0.2 respectively as compared to linearity. Similarly, after glass transition, NCBL reduces by $0.26 \%$ and $0.75 \%$ in Mode- $1,0.17 \%$ and $0.55 \%$ in Mode- $2,0.28 \%$ and $0.87 \%$ in Mode- 3 and $0.29 \%$ and $0.91 \%$ in Mode- 4 with 


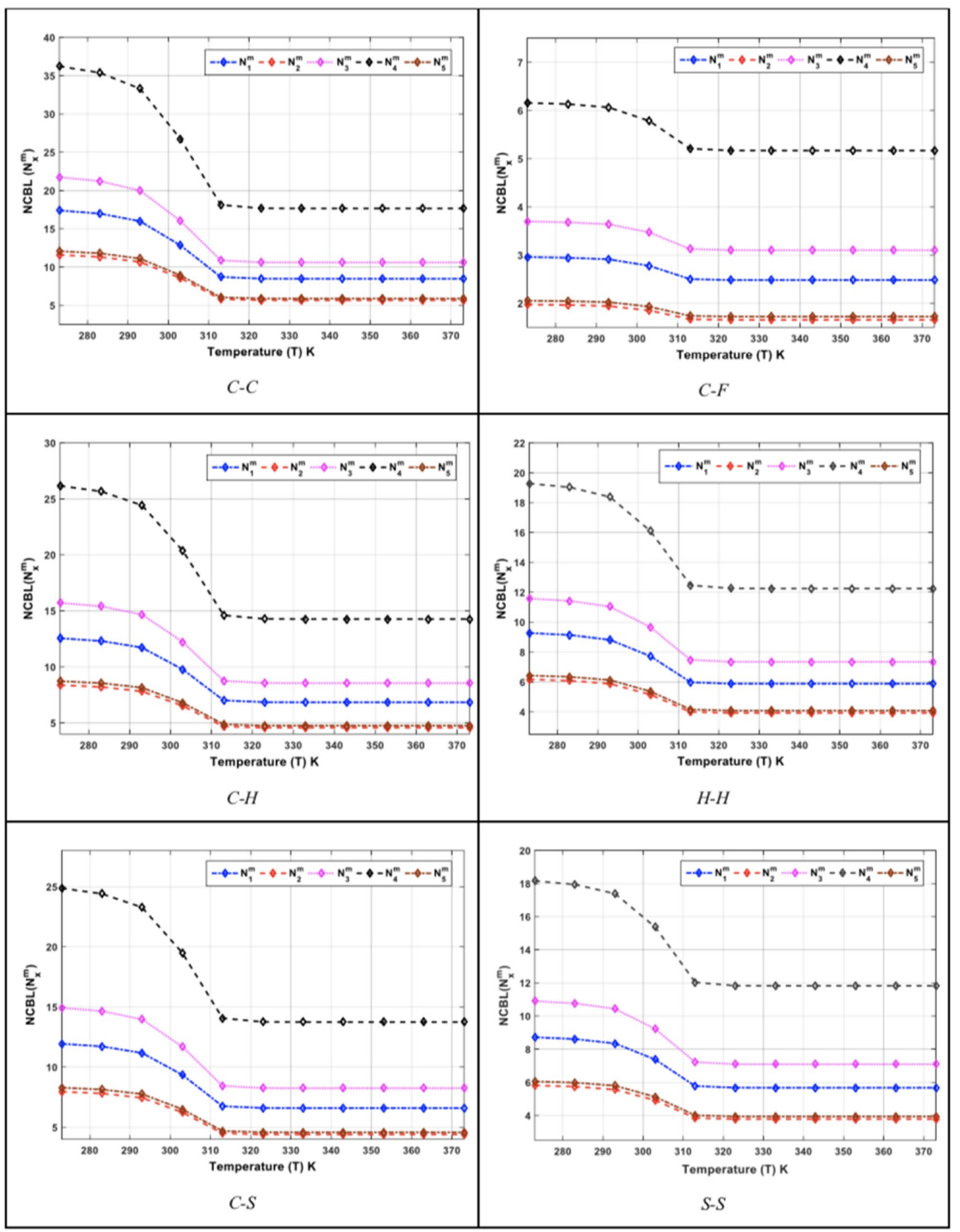

Fig. 5 Non-dimensional critical buckling load (NCBL) under various axial loads with respect to temperature at different $B C s$ 
Table 4 NCBL of SMPC beam with aspect ratio for various loading conditions at six BCs $\left(T=T_{g}\right)$

\begin{tabular}{|c|c|c|c|c|c|c|}
\hline $\mathrm{BCs}$ & $a / h$ & $\mathrm{~N}_{1}^{\mathrm{m}}$ & $\mathrm{N}_{2}^{\mathrm{m}}$ & $\mathrm{N}_{3}^{\mathrm{m}}$ & $\mathrm{N}_{4}^{\mathrm{m}}$ & $\mathrm{N}_{5}^{\mathrm{m}}$ \\
\hline \multirow[t]{4}{*}{$\mathrm{C}-\mathrm{C}$} & 5 & 11.7685 & 7.8456 & 14.7106 & 24.5177 & 8.1725 \\
\hline & 10 & 29.1744 & 19.4496 & 36.4681 & 60.7802 & 20.26 \\
\hline & 20 & 46.2587 & 30.8391 & 57.8234 & 96.3723 & 32.1241 \\
\hline & 50 & 55.3278 & 36.8852 & 69.1597 & 115.2662 & 38.4220 \\
\hline \multirow[t]{4}{*}{$C-F$} & 5 & 2.7178 & 1.8118 & 3.3972 & 5.6621 & 1.8873 \\
\hline & 10 & 2.2816 & 2.1026 & 3.9424 & 6.5706 & 6.5706 \\
\hline & 20 & 3.2855 & 3.2855 & 4.1069 & 6.8449 & 2.2816 \\
\hline & 50 & 3.3244 & 2.2162 & 4.1555 & 6.9258 & 2.3086 \\
\hline \multirow[t]{4}{*}{$\mathrm{C}-\mathrm{H}$} & 5 & 9.0783 & 6.0522 & 11.3479 & 18.9132 & 6.3044 \\
\hline & 10 & 18.8533 & 12.5688 & 23.5666 & 39.2777 & 13.0925 \\
\hline & 20 & 28.5688 & 19.0458 & 35.7110 & 59.5183 & 19.8394 \\
\hline & 50 & 44.6704 & 29.7802 & 55.8380 & 93.0634 & 31.0211 \\
\hline \multirow[t]{4}{*}{$\mathrm{H}-\mathrm{H}$} & 5 & 7.3193 & 4.8795 & 9.1491 & 15.2485 & 5.0828 \\
\hline & 10 & 12.2063 & 8.1375 & 15.2579 & 25.4298 & 8.4766 \\
\hline & 20 & 17.6465 & 11.7643 & 22.0581 & 36.7635 & 12.2545 \\
\hline & 50 & 33.5985 & 22.3990 & 41.9982 & 69.9970 & 23.3323 \\
\hline \multirow[t]{4}{*}{ C-S } & 5 & 8.7090 & 5.8060 & 10.8863 & 18.1439 & 6.0479 \\
\hline & 10 & 17.3944 & 11.5962 & 21.7430 & 36.2383 & 12.0794 \\
\hline & 20 & 23.2691 & 15.5127 & 29.0864 & 48.4774 & 16.1591 \\
\hline & 50 & 25.7048 & 17.1365 & 32.1311 & 53.5518 & 17.8506 \\
\hline \multirow[t]{4}{*}{$S-S$} & 5 & 8.7090 & 5.8060 & 10.8863 & 18.1439 & 6.0479 \\
\hline & 10 & 17.3944 & 11.5962 & 21.7430 & 36.2383 & 12.0794 \\
\hline & 20 & 23.2691 & 15.5127 & 29.0864 & 48.4774 & 16.1591 \\
\hline & 50 & 25.7048 & 17.1365 & 32.1311 & 53.5518 & 17.8506 \\
\hline
\end{tabular}

Table 5 NCBL of clamped SMPC beam with different fiber orientations under various types of loading across glass transition region

\begin{tabular}{llllllr}
\hline Temperature & $\theta^{\circ}$ & \multicolumn{1}{c}{$\mathrm{N}_{1}^{\mathrm{m}}$} & \multicolumn{1}{c}{$\mathrm{N}_{2}^{\mathrm{m}}$} & \multicolumn{1}{c}{$\mathrm{N}_{3}^{\mathrm{m}}$} & $\mathrm{N}_{4}^{\mathrm{m}}$ & $\mathrm{N}_{5}^{\mathrm{m}}$ \\
\hline$T=T_{\beta}\left[\theta^{\circ} / \theta^{\circ} / \theta^{\circ} / \theta^{\circ}\right]$ & $0^{\circ}$ & 50.9473 & 33.9648 & 63.6841 & 106.140 & 35.3800 \\
& $15^{\circ}$ & 47.9034 & 31.9356 & 59.8793 & 99.7988 & 33.2662 \\
& $30^{\circ}$ & 39.5360 & 26.3573 & 49.420 & 82.3666 & 27.4555 \\
& $45^{\circ}$ & 28.0270 & 18.6847 & 35.0338 & 58.3897 & 19.4632 \\
& $60^{\circ}$ & 16.5042 & 11.0028 & 20.6303 & 34.3838 & 11.4612 \\
& $75^{\circ}$ & 8.1156 & 5.4104 & 10.1446 & 16.9076 & 5.6358 \\
$T=T_{g}\left[\theta^{\circ} / \theta^{\circ} / \theta^{\circ} / \theta^{\circ}\right]$ & $0^{\circ}$ & 5.0646 & 3.3764 & 6.3308 & 10.5513 & 3.5171 \\
& $0^{\circ}$ & 47.6178 & 31.7452 & 59.5223 & 99.203 & 33.0679 \\
& $15^{\circ}$ & 44.9489 & 29.9659 & 56.1861 & 93.6436 & 31.2145 \\
& $30^{\circ}$ & 37.4141 & 24.9427 & 46.7676 & 77.9460 & 25.9820 \\
& $45^{\circ}$ & 26.5218 & 17.6812 & 33.1522 & 55.2538 & 18.4179 \\
& $60^{\circ}$ & 14.8993 & 9.9329 & 18.6241 & 31.0403 & 10.3467 \\
& $75^{\circ}$ & 5.9047 & 3.9364 & 7.3808 & 12.3014 & 4.1004 \\
& $90^{\circ}$ & 2.5061 & 1.6707 & 3.1326 & 5.2211 & 1.7403 \\
& $0^{\circ}$ & 43.1655 & 28.7770 & 53.9569 & 89.9281 & 29.9760 \\
& $15^{\circ}$ & 40.9260 & 27.2840 & 51.1576 & 85.2626 & 28.4208 \\
& $30^{\circ}$ & 34.4312 & 22.9541 & 43.0390 & 71.7318 & 23.9106 \\
& $45^{\circ}$ & 24.5576 & 16.3717 & 30.6970 & 51.1617 & 17.0539 \\
& $60^{\circ}$ & 13.3188 & 8.8792 & 16.6485 & 27.7475 & 9.2491 \\
& $75^{\circ}$ & 4.0624 & 2.7082 & 5.0780 & 8.4633 & 2.8211 \\
& $90^{\circ}$ & 0.4262 & 0.2841 & 0.5328 & 0.8880 & 0.2960 \\
\hline
\end{tabular}


Table 6 NCBL of SMPC beam with $a / h=20$ for various laminate orientations at four BCs under $N_{1}^{m}$ type loading $\left(T=T_{g}\right)$

\begin{tabular}{lcccc}
\hline Ply orientation & C-C & C-H & C-S & S-S \\
\hline $90 / 0 / 90 / 0$ & 27.4618 & 18.0427 & 13.2625 & 6.9988 \\
$90 / 0 / 0 / 90$ & 9.28607 & 7.43574 & 4.3180 & 2.2231 \\
$90 / 45 / 45 / 90$ & 5.80351 & 4.9975 & 2.67959 & 1.37342 \\
$45 / 0 / 0 / 45$ & 29.4122 & 19.1232 & 14.2635 & 7.5482 \\
$0 / 0 / 0 / 0$ & 47.6178 & 29.3481 & 24.0251 & 13.0714 \\
$0 / 15 / 15 / 0$ & 47.2883 & 29.1588 & 23.8413 & 12.9646 \\
$0 / 30 / 30 / 0$ & 46.3998 & 28.6495 & 23.3474 & 12.6780 \\
$15 / 30 / 30 / 15$ & 44.0383 & 27.3026 & 22.0439 & 11.9255 \\
$30 / 45 / 45 / 30$ & 36.1146 & 22.8447 & 17.7677 & 9.4959 \\
$30 / 15 / 30 / 15$ & 41.2539 & 25.7261 & 20.5244 & 11.0554 \\
\hline
\end{tabular}

Table 7 NCBL of clamped SMPC beam across glass transition region considering linearity and nonlinearity for different buckling mode shapes under

\begin{tabular}{llllll}
\hline Temperature & $\mathrm{W}_{\max } / \mathrm{h}$ & Mode 1 & Mode 2 & Mode 3 & Mode 4 \\
\hline$T=T_{\beta}$ & 0 & 15.6785 & 17.2363 & 19.7854 & 20.1986 \\
& 0.1 & 15.6566 & 17.2198 & 19.7587 & 20.1717 \\
& 0.2 & 15.5911 & 17.1693 & 19.6776 & 20.0897 \\
$T=T_{g}$ & 0 & 11.8336 & 12.6093 & 14.0886 & 14.3071 \\
& 0.1 & 11.8116 & 12.5936 & 14.0618 & 14.2792 \\
& 0.2 & 11.7468 & 12.5447 & 13.9796 & 14.1940 \\
$T=T_{f}$ & 0 & 8.4944 & 8.8446 & 9.6372 & 9.7520 \\
& 0.1 & 8.4725 & 8.8292 & 9.6103 & 9.7232 \\
& 0.2 & 8.4089 & 8.7803 & 9.5268 & 9.6351 \\
\hline
\end{tabular}

the assumption of nonlinearity of $W_{\max } / h=0.1$ and 0.2 respectively as compared to linearity.

The decline of $24.5 \%, 26.8 \%, 28.8 \%$ and $29.2 \%$ in Mode1, 2, 3 and 4 respectively during the increase of temperature from pre-glass transition condition to $T_{g}$. Moreover, from $T_{g}$ to post-transition, decrease in NCBL is 28.3\%, $30 \%, 31.5 \%$ and $32 \%$ are noticed in Mode $1,2,3$ and 4 respectively. The drastic drop experienced in the NCBL in the different modes of buckling is due to the volatile modulus of SMPC in the transition region, as depicted in Fig. 1. Buckling mode shapes in Mode1, 2, 3 and 4 are indicated in Fig. 6 for $N_{1}^{m}, N_{2}^{m}, N_{3}^{m}, N_{4}^{m}$ and $N_{5}^{m}$ types loading conditions on SMPC laminate beam clamped at $T_{g}$. The difference in the effect of loading condition along the unit length for $N_{2}^{m}, N_{3}^{m}, N_{4}^{m}$ and $N_{5}^{m}$ types of loading conditions are negligible, however for $N_{1}^{m}$ type loading, buckling behavior of Mode-1 is reverse as compared to other loadings.

Some other cases of buckling such as Self buckling of SMPC beam due to its own weight or micro-buckling of the SMPC may occur under the influence of large bending strain at the elevated temperatures after the glass transition temperature of shape memory polymer [42], however in the current work the focus is on the buckling under in plane axial loading.

\subsection{Vibration analysis}

Effect of temperature on the vibrational behavior of the SMPC is depicted in Fig. 7 and Table 8. Sudden drop in the nondimensional frequency is observed within glass transition region from 295 to $330 \mathrm{~K}$, for various loading condition. The values of nondimensional frequency are stable prior and after the glass transition region for all the

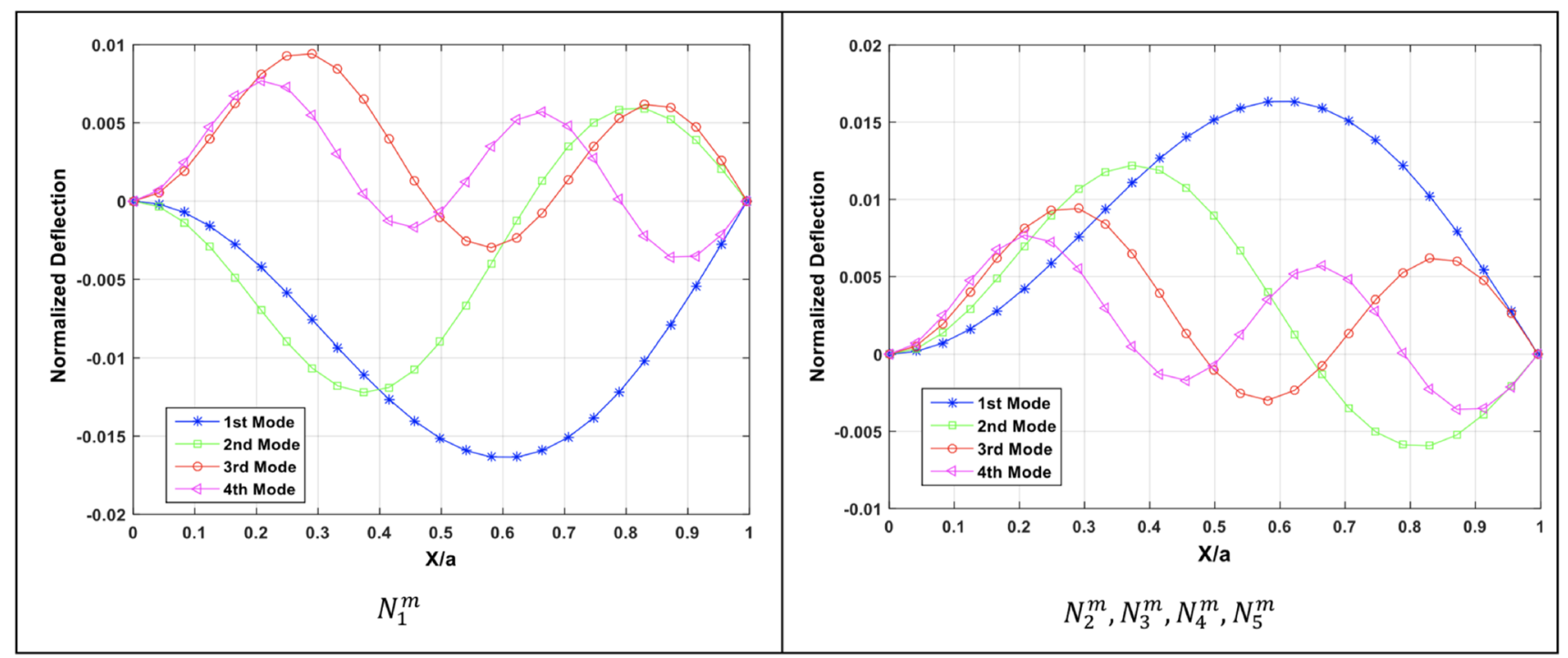

Fig. 6 Buckling mode shapes of symmetric hinged SMPC beam with $\mathrm{a} / \mathrm{h}=20$ for various loading conditions 


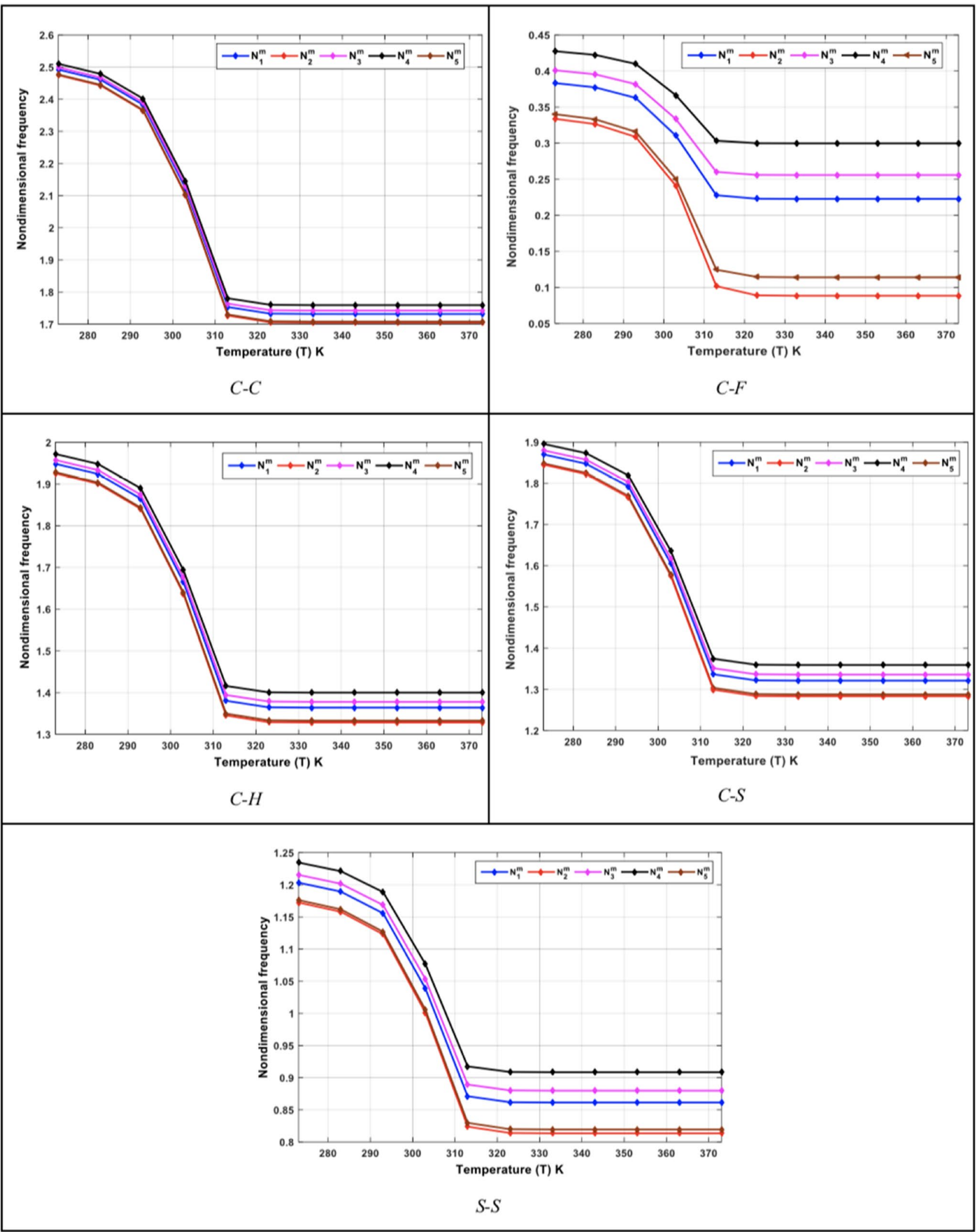

Fig. 7 Non-dimensional frequency under various axial loads with respect to temperature at different BCs 
Table 8 Nondimensional critical frequency of clamped SMPC beam across glass transition region considering linearity and nonlinearity for different buckling mode shapes under

\begin{tabular}{llllll}
\hline Temperature & $\mathrm{W}_{\max } / \mathrm{h}$ & Mode 1 & Mode 2 & Mode 3 & Mode 4 \\
\hline$T=T_{\beta}$ & 0 & 2.3497 & 5.3205 & 8.7824 & 12.0267 \\
& 0.1 & 2.3496 & 5.3202 & 8.7817 & 12.0277 \\
& 0.2 & 2.3492 & 5.3195 & 8.7798 & 12.0290 \\
$T=T_{g}$ & 0 & 2.0310 & 4.5412 & 7.4495 & 10.4467 \\
& 0.1 & 2.0309 & 4.5409 & 7.4488 & 10.4462 \\
& 0.2 & 2.0304 & 4.5402 & 7.4469 & 10.4443 \\
$T=T_{f}$ & 0 & 1.7304 & 3.8119 & 6.2109 & 8.6679 \\
& 0.1 & 1.7302 & 3.8116 & 6.2102 & 8.6672 \\
& 0.2 & 1.7297 & 3.8108 & 6.2081 & 8.6650 \\
\hline
\end{tabular}

$\mathrm{BCs}$, due to the constant modulus in the corresponding temperature. This has also been highlighted in results of buckling analysis discussed in the previous section. Slump in the critical frequency during the glass transition region, is pertinent in all the $\mathrm{BCs}$, although it is magnified in $\mathrm{C}-\mathrm{F}$ boundary condition. Decrease in critical frequency of $39.5 \%, 72.7 \%, 37.5 \%, 28.1 \%$ and $66.2 \%$ has been noticed for $N_{1}^{m}, N_{2}^{m}, N_{3}^{m}, N_{4}^{m}$ and $N_{5}^{m}$ types of load distribution respectively for clamped free (C-F) BC. Moreover, the decline in the frequency before and following the transition region can be similarly observed in other BCs, presented in Fig. 1 .

Influence of BCs and temperature on nondimensional frequency of SMPC under varying loads is indicated in Fig. 7, for the temperature range from 273 to $373 \mathrm{~K}$. Aspect ratio $(a / h)$ of four layered beam is considered to be 5 with fiber orientation of $\left[90^{\circ} / 0^{\circ} / 0^{\circ} / 90^{\circ}\right]$ for C-C, C-F, C-H, C-S and $\mathrm{S}-\mathrm{S}$ boundary conditions. Critical frequency is maximum in C-C boundary condition, whereas it is lowest for C-F, for all the varying loading conditions which is in coherence with the different ideal loading conditions applied on the composite beam. Ascending order of the Ascending order of nondimensional frequency, in terms of $B C s$ is arranged as C-F, S-S, C-S, C-H and C-C. Among all the BCs, temperature can be observed to significantly regulate the vibrational behavior of SMPC beam in the glass transition region which is coherent to the results in Fig. 1 .

Influence of glass transition temperature can be elaborated with the effect of temperature on different modes of vibrations, as stated in Table 8. Nondimensional frequency for four modes of vibrations are compiled in Table 8, for temperature, $T=T_{\beta}, T_{g}$ and $T_{f}$, with respect to linearity and non-linearity. Before the glass transition temperature, at $T=T_{\beta}$, critical frequency decreases by $0.004 \%$ and $0.02 \%$ in Mode- $1,0.005 \%$ and $0.02 \%$ in Mode- $2,0.008 \%$ and $0.03 \%$ in Mode- 3 and $0.008 \%$ and $0.02 \%$ in Mode- 4 with consideration of nonlinearity of $W_{\max } / h=0.1$ and 0.2 respectively as compared to linearity. At glass transition temperature, $T_{g^{\prime}}$ critical frequency decreases by $0.005 \%$ and $0.03 \%$ in Mode- 1 , $0.006 \%$ and $0.02 \%$ in Mode $-2,0.009 \%$ and $0.03 \%$ in Mode- 3 and $0.005 \%$ and $0.02 \%$ in Mode- 4 with consideration of nonlinearity of $W_{\max } / h=0.1$ and 0.2 respectively as compared to linearity. Similarly, after glass transition, $T=T_{f}$, critical frequency reduces by $0.01 \%$ and $0.04 \%$ in Mode- $1,0.008 \%$ and $0.03 \%$ in Mode- $2,0.01 \%$ and $0.05 \%$ in Mode- 3 and $0.008 \%$ and $0.03 \%$ in Mode- 4 with consideration of nonlinearity of $W_{\max } / h=0.1$ and 0.2 respectively as compared to linearity.

Decrement of critical frequency $15.7 \%, 17.2 \%, 17.9 \%$ and $15.1 \%$ in Mode 1, 2, 3 and 4 respectively during the increase of temperature from pre-glass transition condition to $T_{g}$. Moreover, from $T_{g}$ to post-transition, decrease in critical frequency is $14.8 \%, 16.1 \%, 16.6 \%$ and $17 \%$ are noticed in Mode1, 2, 3 and 4 respectively. The sudden decline observed in the critical frequency in the different modes of buckling is due to the detrimental modulus properties of SMPC in the glass transition region, as depicted in Fig. 1.

The application of frequency may lead to the alteration of inherent material properties [43] but in the current study primary focus is on the variation of material properties in the glass transition region of SMPC with the constant frequency.

\section{Conclusion}

Buckling and vibration behavior of SMPC beam subjected to axially heterogeneous in-plane loading conditions are analyzed in this paper through $\mathrm{C}^{\circ}$ continuity based HSDT using Von Karman non-linearity. It was noticed that temperature significantly controls the buckling and vibrations of the SMPC, particularly in the glass transition region of the matrix, because of its volatile behavior.

Based on the thermal dependence and other analysis, it was evident that boundary conditions have pronounced effects on buckling and vibration behavior of SMPC beam. Magnitude of NCBL and critical frequency are maximum for the clamped $B C$, whereas, it is minimum for clamped free $B C$, among the considered boundary conditions for all loading conditions. Among all the considered loadings, deflection of buckling and vibrations are maximum for $\mathrm{N} 4 \mathrm{~m}$ type loading condition and minimum for N2mtype loading. Effect of aspect ratio was considerable during the initial increment from 5 to 20 , but stabilized after 50 . Aspect ratio has a uniform effect on buckling behavior under C-C, CS and S-S boundary conditions, however it is uneven under $\mathrm{C}-\mathrm{F}, \mathrm{C}-\mathrm{H}$ and $\mathrm{H}-\mathrm{H}$. Effect of fiber orientations and laminate stacking is significant on the buckling behavior of the SMPC beam, with maximum values for $0^{\circ}$ fiber orientation and minimum for $90^{\circ}$ orientation. Modes of buckling and vibrations presents more clarity on the behavior of beam 
under different loading conditions and temperature range in which all the modes under different loading have similar trajectory except for $\mathrm{N} 1 \mathrm{~m}$ type of loading condition.

The research presents a comprehensive study of the heterogeneous loading conditions on the buckling and vibrations of the SMPC, which would aid the designers for the efficient development of smart structures such as smart antennas, sensors and actuators. These new experimental developments may present new challenges that will motivate the researchers for novel analysis and applications.

Authors' contributions Nilesh Tiwari: Conceptualization, Drafting, Visualization, Editing; A. A. Shaikh: Review, Rewriting.

Availability of data and material Not applicable.

Code availability Not applicable.

\section{Declarations}

Conflict of interest The authors declare that they have no conflict of interest.

Open Access This article is licensed under a Creative Commons Attribution 4.0 International License, which permits use, sharing, adaptation, distribution and reproduction in any medium or format, as long as you give appropriate credit to the original author(s) and the source, provide a link to the Creative Commons licence, and indicate if changes were made. The images or other third party material in this article are included in the article's Creative Commons licence, unless indicated otherwise in a credit line to the material. If material is not included in the article's Creative Commons licence and your intended use is not permitted by statutory regulation or exceeds the permitted use, you will need to obtain permission directly from the copyright holder. To view a copy of this licence, visit http://creativecommons .org/licenses/by/4.0/.

\section{Appendix 1}

$[B]=\left[\begin{array}{cccccccc}\frac{\partial}{\partial x} & 0 & 0 & 0 & \frac{\partial}{\partial x} & 0 & 0 & 0 \\ 0 & 0 & 0 & \frac{\partial}{\partial x} & 0 & 0 & 0 & \frac{\partial}{\partial x} \\ 0 & -C_{4} \frac{\partial}{\partial x} & -C_{2} \frac{\partial}{\partial x} & 0 & 0 & -C_{4} \frac{\partial}{\partial x} & -C_{2} \frac{\partial}{\partial x} & 0 \\ 0 & C_{1} \frac{\partial}{\partial x} & 0 & C_{1} & 0 & C_{1} \frac{\partial}{\partial x} & 0 & C_{1} \\ 0 & 0 & -3 C_{4} & -3 C_{4} & 0 & 0 & -3 C_{4} & -3 C_{4}\end{array}\right]$

$K_{g}^{(e)}=\frac{1}{2} \int_{A^{e}} B_{g}^{(e) T}\left[N_{n}^{\chi}\right] B_{g}^{(e)} d A$
$D=\int_{-\frac{h}{2}}^{\frac{h}{2}}[T]^{T}[\bar{Q}][T] d z$

\section{References}

1. Leng J, Lan X, Liu Y, Du S (2011) Shape-memory polymers and their composites: stimulus methods and applications. Prog Mater Sci 56(7):1077-1135. https://doi.org/10.1016/j.pmats ci.2011.03.001

2. Wang W, Lu H, Liu Y, Leng J (2014) Sodium dodecyl sulfate/epoxy composite: water-induced shape memory effect and its mechanism. J Mater Chem A 2(15):5441-5449. https://doi.org/10.1039/ C3TA15204A

3. Sun L, Huang WM, Ding Z et al (2012) Stimulus-responsive shape memory materials: a review. Mater Des 33:577-640. https://doi.org/10.1016/j.matdes.2011.04.065

4. Arun DI, Kumar KSS, Kumar BS et al (2019) High glass-transition polyurethane-carbon black electro-active shape memory nanocomposite for aerospace systems. Mater Sci Technol 35(5):596-605. https://doi.org/10.1080/02670836.2019.15750 54

5. Frewin CL, Ecker M, Joshi-Imre A et al (2019) Electrical properties of thiol-ene-based shape memory polymers intended for flexible electronics. Polymers 11(5):902. https://doi. org/10.3390/polym 11050902

6. Zhao W, Liu L, Zhang F et al (2019) Shape memory polymers and their composites in biomedical applications. Mater Sci Eng C 97:864-883. https://doi.org/10.1016/j.msec.2018.12.054

7. He J, Xiao G, Chen X et al (2019) A thermoresponsive microfluidic system integrating a shape memory polymer-modified textile and a paper-based colorimetric sensor for the detection of glucose in human sweat. RSC Adv 9(41):23957-23963. https://doi.org/10.1039/C9RA02831E

8. Karamanli A, Aydogdu M (2019) Buckling of laminated composite and sandwich beams due to axially varying in-plane loads. Compos Struct 210:391-408. https://doi.org/10.1016/j. compstruct.2018.11.067

9. Mathew TC, Singh G, Rao GV (1992) Thermal buckling of crossply composite laminates. Comput Struct 42(2):281-287. https ://doi.org/10.1016/0045-7949(92)90212-I

10. Lee J (1997) Thermally induced buckling of laminated composites by a layerwise theory. Comput Struct 65(6):917-922. https://doi.org/10.1016/S0045-7949(96)00232-5

11. Emam SA, Nayfeh AH (2009) Postbuckling and free vibrations of composite beams. Compos Struct 88(4):636-642. https:// doi.org/10.1016/j.compstruct.2008.06.006

12. Aydogdu M (2006) Buckling analysis of cross-ply laminated beams with general boundary conditions by Ritz method. Compos Sci Technol 66(10):1248-1255. https://doi. org/10.1016/j.compscitech.2005.10.029

13. Aydogdu M (2007) Thermal buckling analysis of cross-ply laminated composite beams with general boundary conditions. Compos Sci Technol 67(6):1096-1104. https://doi. org/10.1016/j.compscitech.2006.05.021

14. Vo TP, Thai H-T (2012) Vibration and buckling of composite beams using refined shear deformation theory. Int J Mech Sci 62(1):67-76. https://doi.org/10.1016/j.ijmecsci.2012.06.001

15. Eltaher MA, Khairy A, Sadoun AM, Omar F-A (2014) Static and buckling analysis of functionally graded Timoshenko 
nanobeams. Appl Math Comput 229:283-295. https://doi. org/10.1016/j.amc.2013.12.072

16. Eltaher MA, Abdelrahman AA, Al-Nabawy A et al (2014) Vibration of nonlinear graduation of nano-Timoshenko beam considering the neutral axis position. Appl Math Comput 235:512-529. https://doi.org/10.1016/j.amc.2014.03.028

17. Nguyen N-D, Nguyen T-K, Nguyen T-N, Thai H-T (2018) New Ritz-solution shape functions for analysis of thermo-mechanical buckling and vibration of laminated composite beams. Compos Struct 184:452-460. https://doi.org/10.1016/j.comps truct.2017.10.003

18. Eisenberger M (1991) Buckling loads for variable cross-section members with variable axial forces. Int J Solids Struct 27(2):135-143. https://doi.org/10.1016/0020-7683(91)90224 $-4$

19. Lee $K$ (2008) Buckling of fibers under distributed axial load. Fibers Polym 9(2):200-202. https://doi.org/10.1007/s1222 1-008-0032-2

20. Li QS (2009) Exact solutions for the generalized Euler's problem. J Appl Mech. https://doi.org/10.1115/1.2937151

21. Duan WH, Wang CM (2008) Exact solution for buckling of columns including self-weight. J Eng Mech 134(1):116-119. https ://doi.org/10.1061/(ASCE)0733-9399(2008)134:1(116)

22. Kumar Panda S, Ramachandra LS (2010) Buckling of rectangular plates with various boundary conditions loaded by non-uniform inplane loads. Int J Mech Sci 52(6):819-828. https://doi. org/10.1016/j.ijmecsci.2010.01.009

23. Nemeth MP (1997) Buckling behavior of long symmetrically laminated plates subjected to shear and linearly varying axial edge loads. NASA Technical Paper, 3659

24. Lopatin AV, Morozov EV (2010) Buckling of the CCFF orthotropic rectangular plates under in-plane pure bending. Compos Struct 92:1423-1431. https://doi.org/10.1016/j.compstruct .2009.10.038

25. Lopatin AV, Morozov EV (2011) Buckling of the SSCF rectangular orthotropic plate subjected to linearly varying in-plane loading. Compos Struct 93(7):1900-1909. https://doi.org/10.1016/j. compstruct.2011.01.024

26. Zhong H, Gu C (2007) Buckling of symmetrical cross-ply composite rectangular plates under a linearly varying in-plane load. Compos Struct 80(1):42-48. https://doi.org/10.1016/j.comps truct.2006.02.030

27. Cagdas IU, Adali S (2013) Buckling of cross-ply laminates subject to linearly varying compressive loads and in-plane boundary restraints. J Thermoplast Compos Mater 26(2):193-215. https ://doi.org/10.1177/0892705711420594

28. Bharat Kalyan J, Bhaskar K (2008) An analytical parametric study on buckling of non-uniformly compressed orthotropic rectangular plates. Compos Struct 82(1):10-18. https://doi. org/10.1016/j.compstruct.2006.11.001

29. Kumar A, Panda SK, Kumar R (2015) Buckling behaviour of laminated composite skew plates with various boundary conditions subjected to linearly varying in-plane edge loading. Int J Mech Sci 100:136-144. https://doi.org/10.1016/j.jimecsci.2015.06.018

30. Mallela UK, Upadhyay A (2014) Buckling of laminated composite stiffened panels subjected to linearly varying in-plane edge loading. Int J Comput Methods Eng Sci Mech 15(1):33-44. https ://doi.org/10.1080/15502287.2013.834000

31. Kim N-I, Lee J (2014) Exact solutions for stability and free vibration of thin-walled Timoshenko laminated beams under variable forces. Arch Appl Mech 84(12):1785-1809. https://doi. org/10.1007/s00419-014-0886-2

32. Eltaher MA, Mohamed SA, Melaibari A (2020) Static stability of a unified composite beams under varying axial loads. Thin-Walled Struct 147:106488. https://doi.org/10.1016/j.tws.2019.106488

33. Westbrook KK, Kao PH, Castro F et al (2011) A 3D finite deformation constitutive model for amorphous shape memory polymers: a multi-branch modeling approach for nonequilibrium relaxation processes. Mech Mater 43(12):853-869. https://doi. org/10.1016/j.mechmat.2011.09.004

34. Gu J, Leng J, Sun H (2017) A constitutive model for amorphous shape memory polymers based on thermodynamics with internal state variables. Mech Mater 111:1-14. https://doi. org/10.1016/j.mechmat.2017.04.008

35. Gu J, Leng J, Sun H et al (2019) Thermomechanical constitutive modeling of fiber reinforced shape memory polymer composites based on thermodynamics with internal state variables. Mech Mater 130:9-19. https://doi.org/10.1016/j.mechm at.2019.01.004

36. Qi HJ, Nguyen TD, Castro F et al (2008) Finite deformation thermo-mechanical behavior of thermally induced shape memory polymers. J Mech Phys Solids 56(5):1730-1751. https://doi. org/10.1016/j.jmps.2007.12.002

37. Shen GL, Hu G, Liu B (2006) Mechanics of composite materials. Science and Technology, Beijing

38. Reddy JN (2014) An introduction to nonlinear finite element analysis, 2nd edn: with applications to heat transfer, fluid mechanics, and solid mechanics. Oxford University Press, Oxford

39. Tiwari N, Shaikh AA (2020) Flexural analysis of thermally actuated fiber reinforced shape memory polymer composite. Adv Mater Res 8(4):337-359. https://doi.org/10.12989/ amr.2019.8.4.337

40. Maiti DK, Sinha PK (1994) Bending and free vibration analysis of shear deformable laminated composite beams by finite element method. Compos Struct 29(4):421-431. https://doi. org/10.1016/0263-8223(94)90111-2

41. Chandrashekhara K, Krishnamurthy K, Roy S (1990) Free vibration of composite beams including rotary inertia and shear deformation. Compos Struct 14(4):269-279. https://doi. org/10.1016/0263-8223(90)90010-C

42. Tiwari N, Shaikh AA (2020) Micro buckling of carbon fiber in triple shape memory polymer composites under bending in glass transition regions. Mater Today: Proc. https://doi.org/10.1016/j. matpr.2020.10.961

43. Bedon C (2019) Issues on the vibration analysis of in-service laminated glass structures: analytical, experimental and numerical investigations on delaminated beams. Appl Sci 9(8):3928. https ://doi.org/10.3390/app9183928

Publisher's Note Springer Nature remains neutral with regard to jurisdictional claims in published maps and institutional affiliations. 